\title{
CARREIRAS POLÍticas NO BRASIL: AMADORES E DE PASSAGEM NAS CAMARAS MUNICIPAIS DE SP E RJ
}

\author{
Rui Tavares Maluf
}

Resumo: O presente artigo é o resultado de uma pesquisa que desenvolvi sobre a carreira política no Brasil, tendo como campo de estudo duas câmaras municipais, a saber, as de São Paulo e Rio de Janeiro, que são as duas maiores do País em número de vagas. A partir dos dados coletados, o texto problematiza a visão tradicional da carreira política, que tem como objeto de análise a Câmara de Deputados. Tal interpretação, por sua vez, tende a concluir que a carreira tem início no município. Minha conclusão é que se faz forçoso admitir carreiras políticas no plural, pois a diversidade é a marca da vida das pessoas que se ocupam da política.

Palavras-Chave: Carreira Política; Vereador; Câmara Municipal de São Paulo; Câmara Municipal do Rio de Janeiro.

Abstract: The present article is the result of my research on political career in Brazil, having as a field of study two city councils; São Paulo and Rio de Janeiro, the country largest ones. From the colected data, this writting put in doubt the traditional conception of political career, the one that takes as its analyses object, specially the Chamber of Deputies. Such interpretation, on its turn, is willing to consider that career starts in the local government (municipalities). My conclusion takes in account political careers in plural, once diversity is the trace of life of people who make politics.

keywords: Political career; Councillor; City Council of São Paulo; City Council of Rio de Janeiro.

\footnotetext{
${ }^{1}$ Doutor em Ciência Política pela USP.
} 
| 122 |

Carreiras políticas no Brasil...

\section{Introdução}

No presente artigo me proponho a descrever e analisar as carreiras políticas no sistema político brasileiro, procurando responder se há outros aspectos importantes a serem observados quando as estudamos pelo ângulo das câmaras municipais de São Paulo (CMSP) e Rio de Janeiro (CMRJ), as duas maiores do País, nas quase três décadas de regime democrático, e enfoco um período de sete eleições (1982 a 2008) de forma a oferecer uma visão de longo prazo (26 anos). Assim, espero reduzir o risco de que conjunturas específicas distorçam as interpretações desenvolvidas, e aproveito para problematizar questões metodológicas inerentes a tal assunto. $\mathrm{O}$ tema vem sendo mais estudado ultimamente, mas em meu entendimento ainda carece de pesquisas mais aprofundadas, pois as existentes utilizam suas linhas explicativas e conceituais tendo como recorte institucional e cronológico os membros de determinadas legislaturas do Congresso Nacional e/ou partidos políticos (LEONI \& PEREIRA \& RENNÓ:2003; SAMUELS:2003), chefes de executivos municipais (ALMEIDA \& CARNEIRO:2003) e partem quase invariavelmente de autores estrangeiros clássicos (SCHLESINGER:1966). Ademais, quando as carreiras são abordadas tendo como unidade de análise as câmaras municipais (como a do Rio de Janeiro), o são na condição de variável dependente de fenômenos políticos mais amplos, tais como o Chaguismo e Brizolismo, combinados à produção legislativa (ALVIM: 2006). Por conseguinte, penso que há espaço suficiente para admitir a idéia de que as carreiras se fazem tanto de forma especializada, pela obtenção regular dos mesmos cargos populares e iguais formas de atuação, quanto de forma multifacetada, isto é, apresentando razoável diversidade nos cargos alcançados e/ou disputados quando se altera o objeto da investigação. Ainda assim, seja qual for a característica do político, a busca da reeleição parlamentar é um ponto possivelmente em comum, incluindo a eleição para o cargo que for viável ao político que foi incapaz de renovar o que detinha a 
fim de que possa mais à frente ter êxito ao pleiteá-lo novamente 2 . $\mathrm{Na}$ interpretação do ex-presidente do Brasil, Fernando Henrique Cardoso, o revés eleitoral não é derrota definitiva: "Assim é o eleitorado, que pratica uma espécie de 'justiça compensatória': quem perde hoje, se não se desmoralizar, tem boa chance de ganhar amanhã. Não é sem razão que os políticos profissionais são sempre candidatos a alguma coisa. Ganhar é melhor, mas perder não chega a ser uma tragédia" (CARDOSO:2006).

O sistema político brasileiro conta com dez cargos de natureza popular e remunerados, nestes incluídos três funções de expectativas para os quais, contraditoriamente, seus candidatos não recebem votos diretamente (vice-prefeito, vicegovernador e vice-presidente), embora só possam alcançá-los mediante a participação em chapa a ser submetida a votos. Três dos 10 cargos são de caráter executivo (presidente da República, governador, e prefeito) e de difícil obtenção pelos homens e mulheres que se dispõem a fazer carreira política, conquanto apresentando graus de dificuldade bem diferente. Os três cargos de vice também são difíceis, embora menos do que os titulares. Dos dez cargos, sete são disputados em eleições simultâneas (federais e estaduais/distritais) e separadas dos outros três cargos (municipais), os quais também se realizam na mesma data, com intervalo de dois anos. Afirmo que os cargos mencionados são de difícil obtenção em conseqüência da rarefeita oferta dos mesmos e da sua maior importância social e política ${ }^{3}$, tratandose este de um fator a elevar o número de interessados e, a isso relacionado os custos econômicos e financeiros envolvidos, e, ainda, o capital político necessário para tal postulação.

${ }^{2}$ O presente artigo e parte dos dados aqui reproduzidos são o resultado da minha tese de doutorado. Por razões de espaço, desconsiderarei as questões teóricas e conceituais que alimentam o presente artigo, recomendando a leitura da tese aos que por estas questões se interessam (MALUF:2006).

${ }^{3}$ Talvez a importância seja discutível para os cargos de vice-prefeito e vice-governador de estados de menor relevância demográfica, econômica, e política. 
| 124 |

Carreiras políticas no Brasil...

O quadro 1 a seguir mostra os cargos públicos abertos à classe política no Brasil.

Quadro 1

Principais cargos das carreiras políticas no Brasil

\begin{tabular}{|c|c|c|}
\hline $\begin{array}{c}\text { EXECUTIVO } \\
\text { Cargos de confiança nas } \\
\text { administrações direta } \\
\text { e indireta }\end{array}$ & $\begin{array}{l}\text { MANDATO POPULAR } \\
\text { ( } 1 \text { ) }\end{array}$ & $\begin{array}{l}\text { JUDICIÁRIO / } \\
\text { TRIBUNAIS DE } \\
\text { CONTAS }\end{array}$ \\
\hline \multicolumn{3}{|c|}{ FEDERAL } \\
\hline $\begin{array}{c}\text { Ministro de Estado } \\
\text { Dirigentes de Autarquias } \\
\text { de Economia Mista }\end{array}$ & $\begin{array}{l}\text { Presidente da República } \\
\text { Vice-presidente da } \\
\text { República } \\
\text { Senador da República } \\
\text { Deputado Federal }\end{array}$ & $\begin{array}{c}\text { Tribunais de contas } \\
\text { da União }\end{array}$ \\
\hline \multicolumn{3}{|c|}{ ESTADO } \\
\hline $\begin{array}{l}\text { Secretário Estadual } \\
\text { Dirigente de Autarquia } \\
\text { e Empresa de } \\
\text { Economia Mista }\end{array}$ & $\begin{array}{c}\text { Governador } \\
\text { Vice-governador } \\
\text { Deputado Estadual }\end{array}$ & $\begin{array}{c}\text { Tribunais de } \\
\text { contas do Estados }\end{array}$ \\
\hline \multicolumn{3}{|c|}{ MUNICÍPIO } \\
\hline $\begin{array}{c}\text { Secretário Municipal } \\
\text { Dirigente de Autarquia } \\
\text { e } \\
\text { Empresa de } \\
\text { Economia Mista }\end{array}$ & $\begin{array}{l}\text { Prefeito } \\
\text { Vice-prefeito } \\
\text { Vereador }\end{array}$ & $\begin{array}{c}\text { Tribunais de contas } \\
\text { do Municipio }\end{array}$ \\
\hline
\end{tabular}

(1) os mandatos populares permitem a eleição para órgãos internos, tais como mesa diretora (direção da instituição), presidente das comissões permanentes e extraordinárias.

Na perspectiva de uma carreira linear ascendente, a descrição do que se passa para os políticos (ao menos para os vitoriosos), apresentaria a seguinte trajetória: da câmara 
municipal para a prefeitura e/ou para a Assembléia Legislativa e/ou governo do Estado; daí para a Câmara dos Deputados, e/ ou governo do Estado; e/ou senado federal; daí para a Presidência da República, passando pelos cargos de vice e suplentes de senador, e por cargos parlamentares de direção (mesa diretora e comissões), executivos da administração direta, dirigentes de fundações e empresas de economia mista (presidências e diretorias), nomeações para conselheiro dos tribunais de contas do município (São Paulo) (presidente e vicepresidente), Estado, União, e, ainda, para o Supremo Tribunal Federal (STF).

Em meu entendimento, tal realidade não existe mais, ou nunca efetivamente existiu ao menos enquanto único padrão, a não ser dentro dos limites mínimos impostos pela realidade de um país no qual em termos agregados a maioria dos cargos de natureza popular se encontra no município e, particularmente, na câmara municipal. O número de cargos se reduz em nível estadual e mais ainda no federal, sendo o afunilamento muito grande. Não obstante, considerando-se o ator político individual, a carreira política se desenvolve em larga medida em termos de especialização, ainda que não evolua, majoritariamente, por intermédio da conquista de cargos populares ou destes dependentes, nos quais os atores políticos apresentam maior vocação e ambição.

No âmbito parlamentar, a obtenção de cargos de direção na mesa diretora, de comissões permanentes, de inquérito e obtenção de relatorias é, também, uma forma de movimentação lateral na carreira muito importante que pode estimular a especialização do representante popular tornando-o, também, de caráter permanente ${ }^{4}$. A obtenção de cargos nos órgãos internos, especialmente nos de direção, pode atender tanto

${ }^{4}$ Permanente não existe ninguém rigorosamente no regime democrático, pois todo político depende da legitimação pelo voto popular. Mas o termo se aplica para os membros da classe política que são reeleitos 
| 126 |

Carreiras políticas no Brasil...

ao político com o perfil voltado para as benesses estritamente materiais da função exercida quanto ao que orienta sua ação baseando-se em compromissos públicos estribado em temas e propostas, e tende a assegurar exposição pública, ao menos por intermédio do trabalho de cobertura feita pela imprensa. Por exemplo, a presidência da instituição legislativa, bem como a de uma comissão, pode atender melhor ao segundo perfil, enquanto o cargo de secretário da mesa ao do representante que visa preferencialmente a obtenção de vantagens materiais. É certo, também, que se a exposição pública resultar da intermediação da imprensa esta tende a ser bem crítica para os parlamentares, especialmente vereadores. Não obstante, a exposição é resultado, igualmente, da relevância do próprio cargo que a depender da forma de atuação gera o contato direto com a base que lhe deu apoio, ou pode lhe vir a dar no futuro.

Concentro-me nas carreiras políticas pelas possibilidades de aperfeiçoamento do regime democrático representativo, o qual se depara com dois grandes desafios: de um lado a ocorrência de renovação expressiva dos parlamentos (embora com tendência declinante), conforme demonstrei em minha dissertação de mestrado sobre a câmara paulistana (1993). E de outro lado (ocorrendo simultaneamente), a manutenção de representantes que atuam basicamente para se manter no poder, independente de qualquer compromisso de interesse público (MALUF:1993; MALUF:2006).

Boa parte do embate acima se deu a partir de pesquisas feitas para o sistema político norte-americano ou de certos países europeus nos quais as eleições parlamentares se processam em termos de distritos com voto majoritário, diferente do que se verifica no Brasil. Quero dizer que o fato de as eleições proporcionais serem de lista aberta (sem que os partidos

indefinidamente para um mesmo cargo popular. No período aqui analisado considero como tal os que se elegeram titulares no mínimo quatro vezes. 
estabeleçam a ordem dos candidatos, com os eleitores podendo votar nas pessoas), combinando-se ao voto proporcional para quase todos os cargos parlamentares brasileiros (à exceção de senador da República), condiciona o cálculo político e, conseqüentemente, pode influenciar em sua trajetória.

Quando mencionei o afunilamento dos cargos de nível municipal para estadual e federal, quis comparar a oferta total de cargos municipais na eleição de 2008 com as nacionais de 2006. Em 2008, a oferta para vereador foi superior a $52 \mathrm{mil}$ cadeiras, para prefeito e vice 5.580 cada, o que é um indicador da maior facilidade para se disputar tal cargo, sobretudo pela facilidade de alteração de domicílio eleitoral, o que permite a algum interessado percebendo a dificuldade de ser eleito em um município maior concorrer a uma vaga em outro menor. Assim, a oferta total municipal chegou a 63.160 no referido ano. Ora, nas eleições nacionais/estaduais de 2006, para a qual se disputou um cargo de presidente, um de vice-presidente da República, um terço de senadores (27), o conjunto da Câmara dos Deputados (513), 27 de governadores, 27 de vicegovernadores, as Assembléias Legislativas estaduais e distrital (1055), a oferta total de cargos públicos foi de somente 1.651. Ou seja, as eleições municipais ofereceram 38,2 vezes mais cargos.

A respeito da dificuldade mencionada é necessário sublinhar que se trata de algo mais complexo. Em municípios muito pequenos em termos demográficos, de pouco eleitorado e de rarefeita expressão econômica, alcançar a indicação para disputar o cargo de prefeito é provavelmente menos difícil que para a de senador da República (e de conquistá-lo), mesmo em diminutas unidades federativas, o que não significa ausência de competição. Apesar disso, são os três mandatos populares por eleição proporcional (vereador, deputados estadual e federal), os que se colocam mais ao alcance dos interessados, ainda que em ordem crescente (supostamente) de dificuldade para a obtenção da legenda para disputá-los.

A partir desta constatação ressalvo alguns aspectos econômicos, sociais e institucionais a serem levados em conta 
| 128 |

Carreiras políticas no Brasil...

na reflexão sobre as carreiras políticas de natureza popular e dos cargos destas decorrentes, os quais são válidos para os três níveis de governo e de poder (municipal, estadual e federal) em maior ou menor medida, e se constituem em incentivos a incidir de forma variada nos agentes individuais ao fazerem suas escolhas. São esses, entre muitos outros, o acesso do político à imprensa, possibilidade de convidar ou convocar autoridade para prestar esclarecimento e depoimento, direito a reeleição ilimitada do parlamentar, de uma reeleição subseqüente e depois reeleição após o intervalo de um mandato para cargos de chefia do Poder Executivo, período de oito anos para senador da República, cargos de assessoria à disposição, recursos materiais, remuneração para todos os cargos públicos, etc.

\section{Questões de método e uma nota metodológica}

Considerando existir mais de uma possibilidade eficiente para estudar as carreiras políticas, a opção a ser escolhida passa pela questão geral que se deseja responder. Assim, escolho as duas câmaras porque se destacam das demais na medida em que a magnitude delas é bem superior as outras ( 55 vagas na paulistana e 51 na carioca) $)^{5}$, bem como seus integrantes são escolhidos para representar os eleitores de metrópoles que dispensam maiores comentários quanto à complexidade dos fenômenos culturais, econômicos, políticos, urbanos e sociais que as cercam. Fazer uma carreira integral ou majoritariamente nessas câmaras, poderia ser entendido como um forte incentivo para alguém, dispensando-o de concorrer a outros cargos de natureza popular (à exceção do de prefeito) porque a ação do vereador destes lugares reuniria aspectos puramente locais como em quaisquer outros municípios e combinados a outros

\footnotetext{
${ }^{5}$ Para constatar esta grandeza, basta registrar que as câmaras de duas outras capitais, Belo Horizonte e Salvador, que vem em segundo lugar, oferecem 41 vagas cada.
} 
propriamente de metrópoles com projeção internacional. Ademais, focar em duas câmaras significa utilizar um método comparativo, o qual, tal como a escolha de várias eleições e legislaturas reduz os perigos embutidos em conclusões que se imaginam tratando de características muito específicas, quando são mais gerais, e, também, o inverso.

\section{Questões a serem respondidas}

Quero responder três questões, sendo uma de caráter geral e duas específicas. A primeira questão, que está implícita no argumento atrás exposto, é a seguinte: o estudo dessas câmaras municipais permite observar outros aspectos sobre as carreiras políticas no Brasil, diferente de quando são estudadas tendo como alvo a Câmara dos Deputados? A segunda questão, de caráter específico, é: tais câmaras se constituem em incentivos suficientes para alguém seguir apenas uma carreira política (vereador), ou no limite nos poderes executivos municipais de suas cidades (prefeito, secretário, presidente de autarquia)?

Para responder a essas duas perguntas relatarei 12 aspectos bem pontuais, a saber:

1. O número de mandatos obtidos pelos vereadores titulares nas duas câmaras;

2 .Número de vereadores eleitos para outro(s) cargo(s) popular(es); populares;

3. Número de mandatos na câmara dos eleitos para outros cargos

4. A identificação dos outros cargos dos vereadores que foram eleitos;

5. Número de vereadores designados para cargos executivos de primeiro escalão;

6. Vereadores nomeados conselheiros de Tribunais de Contas ou órgãos similares em outros níveis;

7. Número de partidos políticos que elegeram vereadores em cada eleição entre 1982 e 2008 e a magnitude (número de vagas) de cada câmara;

8. Número de partidos políticos dos vereadores com dois ou mais mandatos eleitos entre 1982 e 2008;

9. Futuro eleitoral dos vereadores eleitos na eleição base (1982); 
| 130 |

Carreiras políticas no Brasil...

10. Vereadores que tem cargos públicos e políticos no $1^{\circ}$ trimestre de 2009, dentre os eleitos de 1982 a 2008;

11. Identificação dos cargos públicos ocupados pelos vereadores e ex-vereadores:

12. Número de vereadores eleitos para cargos na mesa diretora das câmaras municipais entre 1982 e 2008.

A terceira questão, de caráter ainda mais específico, se propõe a explicar quais são as principais diferenças entre as duas câmaras em questão, e se estas são grandes o suficiente para que sejam consideradas relevantes para as carreiras políticas de quem para essas se elegem.

De certa maneira, enquadrar as duas câmaras é tanto um trabalho sobre as carreiras políticas nos dois maiores legislativos brasileiros, mas igualmente um monitoramento em sentido mais amplo. Dizendo a mesma coisa com maior formalidade; na proposta presente as câmaras municipais e as carreiras políticas se constituem tanto em variáveis dependentes quanto independentes.

Desta exposição metodológica inicial, aproveito para desenvolver uma apreciação crítica sobre os estudos em geral sobre carreiras políticas por estes apresentarem uma limitação de método que me parece recorrente. Mesmo que se queira estudar as carreiras políticas a partir de uma rigorosa delimitação, como, por exemplo, os vereadores em um dado município de determinada legislatura, considero que se incorre em um problema metodológico limitador para conclusões a respeito das opções dos parlamentares caso se ignore todas as candidaturas a cargos públicos disputadas pelos membros da legislatura ao longo de sua vida (especialmente as sem êxito). Dou um exemplo a seguir: se o vereador está no quinto mandato consecutivo na câmara municipal, tal constatação não é suficiente para deduzir que sua escolha de carreira tenha sido pelo legislativo local. Ele pode ter concorrido igual número de vezes para os cargos de prefeito e deputado estadual sem ter conseguido ser eleito. Tal preocupação revela um impacto 
importante quando o estudo da carreira é de caráter agregado porque privilegia o coletivo sobre o individual. Mas, levar isso em conta é uma operação complexa haja vista a dificuldade de obtenção de listas rigorosamente iguais fornecidas pelo Tribunal Superior Eleitoral (TSE) (sobretudo para o período anterior a 1996) e por seus órgãos regionais, quanto aos nomes completos e a grafia dos mesmos, entre outros fatores os quais menciono em minha tese de doutorado (MALUF:2006). Uma possibilidade para se contornar o problema está, obviamente, na delimitação temporal e espacial da pesquisa. Todavia, mesmo adotando tal procedimento, haverá perda significativa de informação.

\begin{abstract}
Amadores e de Passagem
Concentrando-me nos vereadores titulares (diplomados e empossados no início da legislatura) das câmaras municipais de São Paulo (CMSP) e Rio de Janeiro (CMRJ) em sete eleições no decorrer de 26 anos (de 1982 a 2008) fica evidente na tabela 1 a seguir que as características predominantes em termos agregados são as de um e dois mandatos, permitindo classificálos como amadores (somente um mandato, e sem eleição para outros cargos de natureza popular), e/ou de passagem e/ou curta duração (um e no máximo dois mandatos, e depois eleitos para outros cargos). Assim, na câmara de São Paulo, os vereadores de um mandato representaram $46,9 \%$ e, na do Rio, 55,6\% ${ }^{6}$. Somando-os aos de até dois mandatos, expressam $79,2 \%$ na primeira e $78,7 \%$ na segunda. Contudo, como já adverti na parte metodológica, a classificação de vereadores como amadores e/ou de passagem não deve ser confundida como equivalente a desistência, tal como colocado por outros autores que examinam tal característica (FLORENTINO:2008). Frente a esses dados é
\end{abstract}

\footnotetext{
${ }^{6}$ Neste recorte, deixo de lado suplentes que exerceram a vereança ou se efetivaram durante a legislatura, o que só tenderia a aumentar tal realidade. Assim, se o vereador se elegeu em uma legislatura e foi suplente em outra, conto como ele tendo somente um mandato.
} 
| 132 |

Carreiras políticas no Brasil...

seguro afirmar que as duas câmaras pouco retêm representantes populares, o que é alvissareiro para os defensores da alta rotatividade como sendo indicador do vigor do regime democrático.

Tabela 1

Número de Mandatos de Vereadores da CMSP

e da CMRJ em 7 legislaturas

(eleitos titulares de 1982 a 2008)

\begin{tabular}{|c|l|l|l|l|}
\hline Mandatos & CMSP & CMSP \% & CMRJ & CMRJ \% \\
\hline & & & & \\
1 & 90 & 46,9 & 94 & 55,6 \\
2 & 62 & 32,3 & 39 & 23,1 \\
3 & 22 & 11,5 & 22 & 13,0 \\
4 & 12 & 6,6 & 9 & 5,3 \\
5 & 3 & 1,6 & 4 & 2,4 \\
6 & 2 & 1,0 & 1 & 0,6 \\
7 & 1 & 0,5 & 0 & 0 \\
& & & & \\
\hline Total & 192 & 100 & 169 & 100 \\
\hline
\end{tabular}

Fonte: Resultados oficiais das eleições de 1982, 1988, 1992, 1996, 2000, 2004 e 2008. TSE, TRE-SP e TRE-RJ. Dados elaborados pelo autor.

Contudo, a prevalência de vereadores de um e dois (apesar da diferença de 8,7 pontos a mais na do Rio sobre a de São Paulo) não permite por si só responder se tão elevada rotatividade se dá por que o eleitorado a promove e/ou por iniciativa dos próprios parlamentares (isto é, se os próprios titulares é que buscam outros caminhos), ou, em outras palavras, se os parlamentares podem ser classificados como amadores ou de passagem nas duas câmaras. Para uma afirmação consistente seria preciso saber se os edis concorreram ou não a outros cargos 
(mesmo antes de ser vereador nas duas edilidades) e, se o fizeram se foi com ou sem êxito.

Ou seja, a leitura da tabela apresentada isoladamente impede diferenciar quais membros das legislaturas são amadores e quais integram uma classe política em forte competição estando de passagem, classe essa na qual são poucos os sobreviventes, devido, em parte, às regras partidárias e eleitorais.

A depender da grandeza dos números dos eleitos seria possível aceitar a tese de que os vereadores com apenas um mandato se encontram de passagem, mas observando primeiramente o conjunto dos vereadores, constato que os eleitos para outros cargos são minoria nas duas câmaras, embora expressiva (vide tabela 2 a seguir).

Tabela 2

Vereadores que foram eleitos para outros cargos entre 1982 e 2008

\begin{tabular}{|l|l|l|l|l|l|}
\hline $\begin{array}{l}\text { Legislati- } \\
\text { vo }\end{array}$ & Eleitos & $\%$ & $\begin{array}{l}\text { Não } \\
\text { Eleitos }\end{array}$ & $\%$ & N \\
\hline CMRJ & 35 & 20,7 & 134 & 79,3 & 169 \\
\hline CMSP & 44 & 22,9 & 148 & 77,1 & 192 \\
\hline
\end{tabular}

Fonte: Resultados oficiais das eleições municipais e gerais desde 1982. Dados elaborados pelo autor.

Ao desmembrar do conjunto de eleitos para outros cargos os vereadores com apenas um mandato nas duas câmaras ${ }^{7}$, deparei-me com a seguinte realidade: 18 cariocas (51,4\%) e 19 paulistanos $(43,2 \%)$ foram eleitos. A diferença observada entre

${ }^{7} \mathrm{Na}$ realidade isto significa metade de um mandato, porque os vereadores as eleições gerais (nacionais e estaduais) ocorrem pouco menos de dois anos depois de iniciada a legislatura. 
| 134 |

Carreiras políticas no Brasil...

as duas edilidades em termos percentuais na distribuição do número de mandatos é ainda mais realçada nesta variável. Mesmo com superioridade de 8,2 pontos da carioca sobre a paulistana, a minoria da paulistana também é relevante, o que significa que parte dos vereadores com somente um mandato se deve ao fato de terem obtido outro cargo popular. Nota-se, em conseqüência, que uma parcela de políticos se vale da eleição para a câmara municipal para reunir capital político para outros cargos, ou no caso de derrota em outros que detinha usá-la para se recuperar e voltar aos cargos perdidos (ver tabela 3 seguinte).

Tabela 3

Total de Vereadores titulares eleitos para outros cargos populares

\begin{tabular}{|c|c|c|c|}
\hline Legislativo & $\begin{array}{c}\text { Total de } \\
\text { eleitos }\end{array}$ & $\begin{array}{c}\text { Total de } \\
\text { eleitos com 1 } \\
\text { mandato (B) }\end{array}$ & $\begin{array}{c}\% \text { de eleitos } \\
\text { com 1 } \\
\text { mandato } \\
\text { (B/A) }\end{array}$ \\
\hline CMRJ & 35 & 18 & 51,4 \\
\hline CMSP & 44 & 19 & 43,2 \\
\hline
\end{tabular}

Fonte: Resultados oficiais das eleições municipais e gerais desde 1982. Dados organizados pelo autor.

Apesar do avanço interpretativo que se obtém com o cruzamento das informações, ainda é prematuro uma afirmação conclusiva. Para tanto é necessário confrontar as já obtidas com ao menos outras duas, uma das quais descarto recorrer neste espaço ${ }^{8}$. Cruzo-as com a dos partidos políticos que elegeram representantes ao longo dos anos.

\footnotetext{
${ }^{8}$ Seria extremamente trabalhoso correlacioná-las com o total de eleições disputadas, o que inclui as candidaturas fracassadas e para todos os cargos possíveis, bem como a possibilidade de terem ocorrido em outros domicílios eleitorais.
} 


\section{Os Partidos Políticos}

Por se constituírem no veículo legal obrigatório para a postulação dos políticos a qualquer cargo de natureza popular, há várias possibilidades para empregar os partidos em uma análise sobre carreiras políticas. Lanço mão aqui de dois dos recursos mais simples, a saber, o número de partidos que elegeram representantes ao longo das eleições ${ }^{9}$ e as migrações partidárias, isto é, vereadores que mudaram de partido.

Sobre o número de partidos, vale lembrar duas coisas sobre o período em tela que poderiam afetar a possibilidade de êxito das agremiações; em primeiro lugar os partidos comunistas só foram legalizados e puderam competir a partir das eleições de 1985. Portanto, nas eleições de vereadores só poderiam eleger alguém em 1988 porque o mandato daquelas legislaturas foi de seis anos (1983-1988). Em segundo, a magnitude das câmaras, ou seja, a quantidade de vagas aumentou por dois fatores; 1 ) mudança na legislação elaborada sob o regime autoritário que limitava o número máximo de vereadores nos legislativos das capitais para impedir o crescimento das forças de oposição; e, 2) previsão da própria legislação para o aumento de vagas na medida em que se dá o incremento do eleitorado.

É indisfarçável a forte evolução verificada no número de legendas que obtém sucesso para eleger ao menos um vereador. A câmara carioca, que só na legislatura eleita em 1982 teve a mesma magnitude que a paulistana (33 edis) e a partir de então contou menor número de vagas, foi quase sempre superior na quantidade de partidos. Somente no pleito de 2000 é que o número de partidos em São Paulo (13) foi superior ao do Rio (12). Na legislatura eleita em 2008 o Rio de Janeiro assistiu a nada menos do que 21 agremiações elegendo ao menos um representante (seu maior número nas sete -7 - eleições) para 51

${ }^{9}$ Os mais em voga para o âmbito parlamentar são os que levam em conta o Número de Partidos Efetivos (NPE) e o Índice de Fragmentação, os quais se calculam a partir da proporção das bancadas (NICOLAU:1991). 
| 136 |

Carreiras políticas no Brasil...

vagas existentes contra 14 em São Paulo (também o maior número) para 55 cadeiras.

A despeito da diferença entre as duas instituições, é muito grande o número de legendas nos dois legislativos, o que explica em certa medida a existência de amadores e de passagem. A elevada quantidade de partidos na disputa incrementa a de candidatos e gera um forte elemento de incerteza no processo eleitoral ao tornar difícil para o eleitor calcular a viabilidade eleitoral de um candidato de sua preferência. Esta dificuldade acarreta dispersão de votos em maior ou menor grau, reduzindo a competitividade de candidatos politicamente representativos.

Tabela 4

Número de partidos políticos nas

duas câmaras, a partir da eleição e posse (1982-2008)

\begin{tabular}{|l|l|l|l|l|}
\hline Ano da eleição & CMRJ & Magnitude & CMSP & Magnitude \\
\hline 1982 & 05 & 33 & 04 & 33 \\
\hline 1988 & 15 & 42 & 10 & 53 \\
\hline 1992 & 17 & 42 & 09 & 55 \\
\hline 1996 & 11 & 42 & 10 & 55 \\
\hline 2000 & 12 & 42 & 13 & 55 \\
\hline 2004 & 15 & 50 & 12 & 55 \\
\hline 2008 & 21 & 51 & 14 & 55 \\
\hline
\end{tabular}

Fonte: TSE e TREs. Magnitude é o número de vagas (cadeiras) de determinado poder legislativo. 


\section{Migração Partidária}

Ao levar em conta o partido como relevante fator explicativo para as carreiras políticas, o fenômeno da migração partidária precisa ser igualmente considerado, pois as características desse tipo de organização e da legislação eleitoral facilitam sua ocorrência. Como a migração partidária passou a ser prática generalizada na política brasileira, entendo necessário conhecer sua grandeza na eleição dos vereadores com ao menos dois mandatos nas duas câmaras.

Os resultados da migração nas duas câmaras parecem contrariar a expectativa daqueles que supõem que essa prática se revele altamente eficaz para a reeleição, ao menos no legislativo paulistano. Tal questionamento já havia ocorrido no âmbito da Câmara dos Deputados para a qual SCHIMITT (1999) demonstrou que a troca de agremiação afeta marginalmente. $\mathrm{Na}$ edilidade carioca verifica-se que $50,8 \%$ dos titulares com dois ou mais mandatos nas sete eleições foram eleitos por somente

Tabela 4.1.

Número de partidos pelos quais vereadores com 2 ou mais mandatos foram eleitos para as câmaras do Rio de Janeiro e São Paulo (1982-2008),

\begin{tabular}{|c|c|c|c|c|c|c|c|c|}
\hline \multicolumn{5}{|c|}{ CMRJ } & \multicolumn{4}{|c|}{ CMSP } \\
\hline Mandatos & 1 & 2 & 3 & 4 & 1 & 2 & 3 & 4 \\
\hline 2 & 34,7 & 17,3 & - & & 48,0 & 12,7 & & \\
\hline 3 & 10,7 & 12,0 & 6,5 & & 13,7 & 6,9 & 1,0 & \\
\hline 4 & 2,7 & 4,0 & 5,3 & & 6,9 & 2,0 & 2,0 & \\
\hline 5 & 2,7 & 2,7 & . & & 2,0 & 2,0 & F & . \\
\hline 6 & - & . & - & 1,3 & 1,0 & . & 1,0 & - \\
\hline 7 & . & . & . & . & 1,0 & . & . & . \\
\hline PARCIAIS & 50,8 & 36,0 & 11,8 & 1,3 & 72,6 & 30,5 & 4,0 & - \\
\hline
\end{tabular}

Fonte: resultados oficiais das eleições municipais de 1982 a 2008. Dados elaborados pelo autor. 
| 138 |

Carreiras políticas no Brasil...

um partido, enquanto em São Paulo este número alcança importantíssimos $72,6 \%$.

Ou seja, no tema migração partidária, a despeito das semelhanças existentes entre as CMRJ e CMSP é possível apontar as seguintes diferenças: o único vereador a ter sido eleito nas sete disputas, Jooji Hato (SP), o foi por apenas uma organização $(\text { o PMDB })^{10}$ e um das mais relevantes em todo o País. Na câmara carioca o vereador mais antigo, Jorge Pereira Souza, com seis mandatos, elegeu-se e reelegeu-se em quatro processos de filiação, ainda que por três diferentes partidos e, apenas um destes de importância nacional (PFL/DEM).

Os grandes partidos nacionais são efetivamente mais importantes para a eleição em São Paulo do que no Rio, pois é bem menor o número de partidos que elegeram ao menos um vereador, bem como a migração partidária é minoritária dentre os eleitos. Desmembrando a tabela anterior de forma a identificar a ordem das associações entre número de mandatos e de partidos pelos quais os vereadores se consagraram nas urnas, a primeira posição para as duas Edilidades é de vereadores com um partido e dois mandatos. Entretanto, a grandeza na câmara do Rio é de somente $34,7 \%$ de todos os vereadores, enquanto na de São Paulo é de $48,0 \%$, perfazendo diferença de quase 14 pontos. Constatei, ainda, que na segunda posição, as duas câmaras apresentam posições diferentes. Na carioca, é de dois partidos e dois mandatos $(17,3 \%)$ e na paulistana continua sendo de um partido, porém com três mandatos $(13,7 \%)$, dado este que reforça a importância na diferença de um ou mais partidos na trajetória dos vereadores dos dois legislativos.

\footnotetext{
${ }^{10}$ No critério que empreguei para contar a migração de partidos, considero tendo sido eleito por três agremiações alguém que se elegeu por dois partidos, mas de forma intercalada. Exemplo: na primeira eleição foi eleito pelo PMDB, na segunda pelo PSDB, e na terceira voltou a se eleger pelo PMDB. Por outro lado contei como apenas um aos partidos que se fundiram a outros e/ou mudaram de nome, tais como PDS/PPB/ PP, PFL/DEM e PL/PR.
} 


\section{Onde estavam no primeiro trimestre de 2009 os eleitos de} 1982? ${ }^{11}$

Para responder a pergunta deste tópico faço esclarecimento preliminar: as possibilidades de percurso são diferentes para os que disputam e se elegem pela primeira vez em cada uma destas legislaturas (sem desconsiderar a idade), o que me faz excluir os parlamentares titulares estreantes da legislatura eleita em 2008, a fim de minimizar distorções.

Observando primeiramente os eleitos em 1982 em face às legislaturas seguintes em termos agregados, constata-se que estes foram escasseando nas duas câmaras. Na do Rio de Janeiro já não havia mais nenhum titular dentre os eleitos em 2000 e empossados no ano seguinte, enquanto na de São Paulo, apenas um vereador continuou sendo eleito ininterruptamente (o já mencionado Jooji Hato).

${ }^{11}$ Das sete legislaturas eleitas, a de 1982 foi a única a contar com mandato de seis anos de duração. Daí para frente, as demais passaram a quatro anos. 
Tabela 5

Futuro nas câmaras municipais dos vereadores cariocas e paulistanos Eleitos em 1982 (Ano base)

\begin{tabular}{|l|l|l|l|l|l|l|}
\hline Legislaturas & CMRJ & $\%(1)$ & $\%(2)$ & CMSP & $\%(1)$ & $\%(2)$ \\
\hline $1988-1992$ & 11 & 33,3 & 26,2 & 20 & 60,6 & 36,4 \\
\hline $1993-1996$ & 5 & 15,2 & 11,9 & 9 & 27,3 & 17,0 \\
\hline $1997-2000$ & 3 & 9,1 & 7,1 & 2 & 6,1 & 3,6 \\
\hline $2001-2004$ & 0 & - & & 1 & 3,0 & 1,8 \\
\hline $2005-2008$ & 0 & - & & 1 & 3,0 & 1,8 \\
\hline $2009-2012$ & 0 & - & & 1 & 3,0 & 1,8 \\
\hline
\end{tabular}

Fontes TSE, TRE-SP, TRE-RJ. Dados elaborados pelo autor.

(1) - Percentual sobre a magnitude da legislatura (1983-1988), a saber: 33 vagas nas 2 câmaras.

(2) - Percentual sobre a magnitude de cada legislatura seguinte.

Procurando visualizar as trajetórias individuais dos vereadores eleitos em 1982 observa-se o seguinte quadro no primeiro trimestre de 2009: em São Paulo, pelo menos cinco deles faleceram entre os anos de 1989 e 2007 (15,2\% dos 33), os quais pertenciam a gerações que se encontravam da média de idade para cima dentre os titulares da legislatura empossada em $1983^{12}$. Sete exerciam cargos públicos de natureza popular ou dela derivados, sendo seis legisladores. Dos seis, cinco eram

${ }^{12}$ Haveria, portanto, a chance de 28 continuarem na carreira política no primeiro trimestre de 2009. 
deputados federais (estando um deles licenciado e ocupando o cargo de secretário municipal de Esportes, Lazer e Recreação na capital), e um continuava vereador (Hato). O outro (derivado de cargo popular) era conselheiro do Tribunal de Contas do Município (TCM) desde o final de $1988^{13}$.

No Rio de Janeiro, dois vereadores de $33(6 \%)$ eleitos em 1982 já faleceram, sendo que um deles ainda voltou à câmara duas legislaturas mais tarde (1993-1996). Assim sendo, 31 vereadores daquela legislatura poderiam estar fazendo alguma carreira política no início de 2009. Mas, apenas dois vereadores de um total de cinco dentre os que deram prosseguimento à carreira ainda se encontravam em cargos políticos (nenhum na câmara municipal), embora a idade da maioria permitisse uma carreira longeva. Um dos dois vereadores daquela legislatura, Nestor Guimarães Martins da Rocha (PDT), se tornou e ainda era conselheiro do Tribunal de Contas do Município, cargo que é praticamente de nomeação exclusiva daqueles que detém ou detiveram mandato popular, especialmente de vereador. Antes dele, outro colega de legislatura, Sérgio Cabral Santos (PMDB), pai do governador do Rio de Janeiro (2007-2010), também foi nomeado conselheiro do Tribunal, mas já estava compulsoriamente aposentado no final de 2007 por ter completado a idade limite de 70 anos. Além de Nestor Rocha, há o caso de maior destaque em âmbito nacional que é o de Benedita Souza da Silva Sampaio (Benedita da Silva). A partir daquela legislatura, ela foi eleita senadora da República, mais tarde vice-governadora do Rio de Janeiro e se tornou governadora após o titular do cargo, Antony Garotinho, renunciar, além de ministra de Estado do Bem Estar Social, e no primeiro trimestre de 2009 era secretária estadual de Assistência Social. Houve dois outros vereadores que obtiveram cargos públicos de natureza popular, conquanto nenhum deles mais os exercesse.

${ }^{13}$ Há também um ex-vereador daquela legislatura que era diretor do instituto da Assembléia Legislativa de São Paulo, mas não considero tal cargo diretamente ligado aos membros da classe política. 
| 142 |

Carreiras políticas no Brasil...

E onde estavam no primeiro trimestre de 2009 os eleitos de 1982 a 2008 ?

Somando as legislaturas de 1982 às outras cinco que foram eleitas de 1988 a 2008 (excluindo-se apenas os vereadores já mencionados), obtém-se um total de 177 em São Paulo e 151 no Rio de Janeiro. Destas turmas, 60 (33,9\%) da câmara paulistana e 54 da câmara carioca $(33,5 \%)$ continuavam na vida pública ocupando mandatos e/ou cargos executivos, ou ainda como conselheiros. Como se verifica em termos percentuais, as participações em São Paulo e Rio de Janeiro são praticamente iguais, fatos estes que sugerem características comuns na distribuição das carreiras políticas no sistema político brasileiro (ver tabela 8 a seguir). Contudo, ao tomar como referência os totais das câmaras isoladamente, manifestam-se diferenças importantes dentre os eleitos e/ou nomeados para outros cargos públicos, a saber: somente $3,3 \%$ dos paulistanos ocuparam cargos de secretário municipal contra $13 \%$ dos cariocas; não mais do que 6,7\% dos paulistanos elegeram-se deputado estadual contra $13 \%$ dos cariocas; e 16,7\% dos paulistanos tornaram-se deputado federal em algum momento versus $11,1 \%$ dos cariocas.

Não é demais lembrar que os prefeitos Eduardo Paes (PMDB) (2009-2012) e Gilberto Kassab (DEM) (2009-2012 e 2006-2008) do Rio de Janeiro e São Paulo respectivamente, saíram das câmaras municipais das duas capitais, mas não em eleições subsequentes. Antes disso, foram eleitos para deputado estadual (Kassab) e federal (Paes e Kassab) e vice-prefeito (Kassab) e podem ser classificados como vereadores de passagem por terem exercido somente um mandato em suas edilidades. 
Tabela 6

Mandatos elou cargos executivos exercidos no início de 2009, Dentre os vereadores eleitos de 1982 para frente

\begin{tabular}{|c|c|c|c|c|}
\hline \multicolumn{3}{|c|}{ CM RJ } & \multicolumn{2}{|c|}{ CM SP } \\
\hline INSTITUIÇÃO & $\mathbf{N}$ & Em \% & $\mathbf{N}$ & Em \% \\
\hline Vereador* & 39 & 65,0 & 30 & 55,6 \\
\hline Prefeito & 1 & 1,7 & 1 & 1,9 \\
\hline $\begin{array}{l}\text { Secretário } \\
\text { Municipal }\end{array}$ & 2 & 3,3 & 7 & 13,0 \\
\hline $\begin{array}{r}\text { Secretário } \\
\text { Estadual }\end{array}$ & 0 & - & 1 & 1,9 \\
\hline $\begin{array}{r}\text { Conselheiro } \\
\text { do TCM }\end{array}$ & 3 & 5,0 & $\mathbf{1}$ & 1,9 \\
\hline $\begin{array}{r}\text { Deputado } \\
\text { Estadual }\end{array}$ & 4 & 6,7 & 7 & 13,0 \\
\hline $\begin{array}{r}\text { Deputado } \\
\text { Federal }\end{array}$ & 10 & 16,7 & 6 & 11,1 \\
\hline $\begin{array}{r}\text { Ministro do } \\
\text { governo } \\
\text { Federal }\end{array}$ & 0 & - & 1 & 1,9 \\
\hline Senador & 1 & 1,7 & 0 & - \\
\hline Total & 60 & 100 & 54 & 100 \\
\hline $\begin{array}{r}\text { Títulares } \\
\text { eleitos 1982- } \\
2008^{*}\end{array}$ & 177 & & 151 & \\
\hline $\begin{array}{r}\% \text { sobre o } \\
\text { total de } \\
\text { eleitos }\end{array}$ & 33,9 & & 33,5 & \\
\hline
\end{tabular}

*excluídos os que estão em primeiro mandato a partir de 2008 e sem qualquer outro cargo eletivo anterior. 
| 144 |

Carreiras políticas no Brasil...

\section{Acesso aos cargos de direção}

Os cargos da mesa diretora dos legislativos são atrativos para se fazer a carreira política no próprio município (incluindo as presidências de comissões permanentes, de estudos, ou de inquérito, não abordadas nesse artigo), mas serão sempre ocupados por minorias devido a sua escassez. Tais minorias poderão ser mais ou menos estreitas a depender de ao menos três fatores, a saber: 1) a rotatividade geral a cada eleição ser grande o suficiente para novos representantes populares; 2) rotatividade interna entre os vereadores, evitando que ocorra concentração por parte de alguns; e 3) regimento interno que propicie tal rotatividade, reduzindo o tempo do mandato e/ou limitando direito à reeleição dos integrantes da mesa diretora.

A participação dos vereadores das duas câmaras nas mesas diretoras pode ser considerada alta nas duas edilidades, embora tal grandeza seja tecnicamente uma minoria (veja a tabela seguinte). Na câmara paulistana, $37,3 \%$ do total dos membros de sete legislaturas incompletas tiveram algum cargo na mesa, enquanto $25,4 \%$ o tiveram na carioca. Dividindo a participação nos cargos da mesa diretora pelo número de mandatos em cada legislativo observo que o percentual é bem superior para os edis que tiveram até três mandatos nas câmaras do que para os que tiveram de quatro a mais mandatos $(27,1 \%$ na paulistana e $19,5 \%$ na carioca, contra $7,3 \%$ e 5,9\% respectivamente).

Ora, se vereadores com até três mandatos são classificados como amadores, de passagem e/ou quase permanentes, deve-se reconhecer que tal condição não os tem impedido de assumir os postos de comando. Talvez, para os vereadores cujas carreiras políticas sejam feitas de passagem pela câmara possa-se dizer que a obtenção dos cargos de direção seja importante para aumentar seu capital político eleitoral, uma vez que a infraestrutura dos cargos da mesa pode otimizar o tempo de atuação política junto aos eleitores. E, assim sendo, se esforçariam mais para obtê-los do que seus colegas classificados como quase permanentes ou permanentes. 
Tabela 7

Vereadores que foram eleitos para a Mesa Diretora(1983-2009), Segundo o número de mandatos na câmara municipal

\begin{tabular}{|c|c|c|c|c|c|c|}
\hline & \multicolumn{3}{|c|}{ CMSP } & \multicolumn{3}{|c|}{ CMRJ } \\
\hline $\begin{array}{c}\text { Cargo na } \\
\text { mesa điretora }\end{array}$ & 1 a 3 & 4 ou mais & TOTAL & 1 a 3 & 4 ou mais & TOTAL \\
\hline Presidente & 13 & 3 & 16 & 7 & 2 & 9 \\
\hline $\begin{array}{l}1^{0} \text { Vice } \\
\text { Presidente }\end{array}$ & 6 & 6 & 12 & 9 & 3 & 12 \\
\hline $\begin{array}{l}2^{\circ} \text { Vice } \\
\text { Presidente }\end{array}$ & 13 & 5 & 18 & 10 & 3 & 13 \\
\hline Presidente $3^{0}$ Vice & - & 1 & 1 & - & - & - \\
\hline $1^{0}$ Secretário & 14 & 5 & 19 & 9 & 2 & 11 \\
\hline $2^{\circ}$ Secretário & 13 & 3 & 16 & 7 & 4 & 11 \\
\hline $3^{0}$ Secretário* & 1 & 0 & 1 & - & - & - \\
\hline Corregedor** & - & 1 & 1 & - & - & - \\
\hline Freqüência & 60 & 24 & 84 & 42 & 14 & 56 \\
\hline $\begin{array}{r}\text { Total de } \\
\text { Vereadores }\end{array}$ & 52 & 14 & 66 & 33 & 10 & 43 \\
\hline $\begin{array}{r}\text { Titylares } \\
\text { eleitos } \\
1982-2008 \text { (1) }\end{array}$ & 177 & 177 & 177 & 151 & 151 & 151 \\
\hline$\%$ sobre (1) & 29,4 & 7,9 & 37,3 & 21,9 & 6,6 & 28,5 \\
\hline $\begin{array}{r}\text { Total de } \\
\text { eleitos } \\
1982-2008\end{array}$ & 192 & 192 & 192 & 169 & 169 & 169 \\
\hline $\begin{array}{c}\% \text { sobre total } \\
\text { de eleitos }\end{array}$ & 27,1 & 7,3 & 34,2 & 19,5 & 5,9 & 25,4 \\
\hline
\end{tabular}

Fonte: Diário Oficial do Município. Seção da CMSP.

Observação: exclui os vogais/suplentes da mesa, pois não tem participação efetiva na mesa.

*Cargos existiram por somente parte de uma legislatura

na CMSP **Só a CMSP possui o cargo no âmbito da MD.

(1) Excluídos os que estão em primeiro mandato a partir da eleição de 2008 e sem qualquer outro cargo eletivo anterior. 
| 146 |

Carreiras políticas no Brasil...

Mas, independentemente do número de mandatos como vereador, o cargo mais importante da mesa diretora, a presidência, esteve na câmara do Rio sempre ocupado por membros da base de sustentação do prefeito e de seu próprio partido na maioria das vezes. Na de São Paulo isso se deu com elevada freqüência, mas em 1986, 1991, 1992 o cargo foi ocupado por vereadores de partidos de oposição.

\section{Considerações finais}

Quanto à primeira questão a que me propus responder com base nos dados até aqui analisados entendo que estes são suficientes para reforçar minha interpretação de que as carreiras políticas no Brasil quando são vistas pelas maiores câmaras de vereadores do País oferecem outro ângulo de compreensão, pois se fazem em trajetórias multifacetadas, mas apresentando ligeira tendência à especialização. Ou seja, não se faz um percurso rigorosamente ascendente; as carreiras podem ser significativamente acidentadas para alguns como também especializadas para outros. O município, em particular a câmara municipal (ao menos das duas maiores metrópoles brasileiras), pode ser tanto ponto de partida para uma carreira vertical, quanto de permanência, de rearticulação, ou mesmo de chegada (neste último caso residualmente). A especialização talvez não seja propriamente a expressão de um maior envolvimento com a atuação em um nível de governo e/ou de um tema ou conjunto por parte dos que assim são classificados, mas sim a necessidade de reduzir a incerteza sobre o processo eleitoral, ou seja, sobre a reeleição parlamentar haja vista que o sistema eleitoral é proporcional com listas abertas, tornando difícil para o candidato (e mais ainda para o eleitor) identificar com clareza os candidatos e, especialmente, calcular a oportunidade de êxito. Em relação à segunda questão, que considero relacionada a anterior, observo que as duas maiores câmaras municipais não se constituíram em 
incentivos suficientemente fortes para reter representantes populares no período histórico (1982-2008) em tela.

No tocante a terceira questão, comparando as câmaras do Rio de Janeiro e de São Paulo, as diferenças que ambas evidenciam parecem estar propriamente no tamanho de cada uma e não na essência. Essas diferenças se revelam no crescimento da pulverização partidária como meio de acesso as vagas na câmara, na maior migração partidária, bem como na menor retenção de vereadores na edilidade carioca. Dos edis profissionais, isto é, dos que vivem para e da política no sentido formulado pelo sociólogo alemão Max Weber (2005) ${ }^{14}$, os cariocas tendem em maior número a passar pela câmara, enquanto os paulistanos a nesta permanecer mais tempo, ou somente nela atuar. Se as dessemelhanças estão na grandeza é importante ressaltar que há um núcleo comum no qual se verifica que a expressiva maioria dos vereadores tem somente um mandato na câmara (ainda que o peso relativo aponte para uma redução significativa no decorrer das legislaturas) como se houvesse uma barreira legal para que eles se candidatassem a reeleição.

Penso que o interesse a respeito dessas considerações é grande para analistas e para os que desejam uma vida pública municipal de maior qualidade (sobretudo em municípios metrópoles) e o aperfeiçoamento do sistema democrático. A realização desse desejo demandaria um conjunto de representantes populares mais qualificados no lidar com os temas tantos pontuais quanto gerais da cidade e estes em suas interfaces com os referentes aos da esfera nacional e mesmo internacional. Com poucas pessoas fazendo carreira política na câmara municipal, especialmente na do Rio de Janeiro, tal expectativa fica frustrada.

14 É necessário recordar como já havia feito em minha tese (MALUF:2006) que Weber "afasta a idéia de exclusão" na dualidade entre as pessoas que vivem para a política das que vivem da política, "admitindo-a apenas em sentido econômico". 
| 148 |

Carreiras políticas no Brasil...

\section{Bibliografia:}

\section{Livros}

CARDOSO, Fernando Henrique - A Arte da Política. Civilização Brasileira. Rio de Janeiro. 2006

DOWNS, Antony - Uma Teoria Econômica da Democracia. São Paulo. Edusp.1999

MICHELS, Robert - Sociologia dos Partidos Políticos. Brasília. UNB. 1982

MOSCA, Gaetano - The Ruling Class. New York McGrawHill.1939

NICOLAU, Jairo - Multipartidarismo e Democracia. FGV. 1996

SAMUELS, David - Ambitions, Federalism and Legislative Politics in Brazil. Cambridge New York. Cambridge University Press. 2003.

SCHLESINGER, Joseph - Ambition and Politics: Political career in the United States. Chicago. R. MC. Nally.1996

WEBER, Max - A Política como Vocação. São Paulo. Martin Claret. São Paulo. 2005

\section{Artigos em Periódico}

ALMEIDA, Maria Hermínia e Leandro Piquet Carneiro. Liderança Local, Democracia e Políticas Públicas no Brasil. Opinião Pública. Campinas. Vol IX. No 1. Página 124-147. 2003

FLORENTINO, Renata (2008) - Saindo de Cena: Parlamentares que desistem da disputa eleitoral (1990-2006). Revista de Sociologia e Política. Vol. 6. N. 30. Curitiba.

LEONI, Eduardo, Carlos Pereira e Lucio Rennó - Estratégias para Sobreviver Politicamente. Escolhas nas Câmaras de Deputados do Brasil. Opinião Pública. Volume IX, número 01.2003.

SCHMITT, Rogério. Migração Partidária e Reeleição na Câmara dos Deputados. Revista Novos estudos. Cebrap. São Paulo. 1999. 


\section{Dissertações e teses}

ALVIM, Anna Rita SantAna (1993) - A Volta da Gaiola de Ouro: uma análise do campo político da Câmara Municipal do Rio de Janeiro (1976-1996). Dissertação de Mestrado. História Social. Universidade Severino Sombra (USS). Vassouras (RJ).

MALUF, Rui Tavares (1993) - A Câmara Municipal de São Paulo na IX Legislatura (1983-1988) e o Processo Decisório do IPTU. Dissertação de Mestrado. Ciência Política. UNICAMP.

MALUF, Rui Tavares (2006) - A Carreira Política na Câmara Municipal de São Paulo. Tese de Doutorado. Ciência Política. USP.

\section{Outras fontes}

Câmara Municipal do Rio de Janeiro. Diário Oficial do Poder Legislativo.

Diário Oficial do Município do Rio de Janeiro. Poder Executivo.

Diário Oficial do Município de São Paulo.

Diário Oficial do Estado do Rio de Janeiro. Poderes Executivo e Legislativo.

Diário Oficial do Estado de São Paulo. Poderes Executivo e Legislativo.

Tribunal Superior Eleitoral (TSE).

Tribunal Regional Eleitoral de São Paulo (TRE-SP).

Tribunal Regional Eleitoral do Rio de Janeiro (TRE-RJ). 